\title{
Flow Regime and Ecosystem Interactions in Spring-Dominated Streams: Implications for Selecting Instream Flow Methods
}

\author{
Dudley W. Reiser ${ }^{(1)}$, David Chapin ${ }^{(2)}$, Paul DeVries ${ }^{(1)}$, \\ and Michael P. Ramey ${ }^{(1)}$
}

Corresponding Author: Dudley W. Reiserdreiser@r2usa.com

\begin{abstract}
Spring-dominated streams (SDS) are known to differ from runoff-dominated streams (RDS) in a number of ways. Stability of flow and temperature are two characteristics most often associated with spring-dominated streams, but other ecosystem attributes may also differ. The effects of altered flow regimes may also differ between these two system types. Relationships between flow and fish habitat have been widely studied in RDS, and a variety of instream flow methodologies/models have been developed to quantify these relationships. The applicability of these methods and models to SDS has not been tested. In this paper, we summarize information on spring-dominated streams, addressing the questions of (1) how key habitat components of salmonid fish differ between spring- and runoff-dominated streams and (2) how changes in flow regime may affect spring- and runoff-dominated streams differently. Implications for selecting/ developing methods applicable for evaluating flow needs of spring-dominated streams and impacts associated with water abstraction are discussed.
\end{abstract}

Key words. - spring dominated streams, runoff dominated streams, instream flow methods, invertebrates, water quality

\section{INTRODUCTION}

Spring-dominated streams (SDS) are known to differ from runoff-dominated streams (RDS) in a number of ways. Stability of flow and tempera- ture are the two characteristics most often associated with spring-dominated streams, but numerous other ecosystem attributes may also be different from runoff dominated streams, such as $\mathrm{pH}$, nutrient levels, dissolved gasses, invertebrate and fish commu-

(1) Dudley W. Reiser, Paul DeVries, Michael Ramey, R2 Resource Consultants, 15250 N.E. $95^{\text {th }}$ St., Redmond, Washington, 98052-2518.

(2) David Chapin, Seattle Public Utilities, Cedar River Watershed. 19901 Cedar Falls Road SE, North Bend, Washington 98095 
nities, and aquatic macrophyte and riparian plants. Because ecosystem characteristics may vary between spring- and runoff-dominated streams, the effects of altered flow regimes (primarily due to flow abstraction and regulation associated with municipal and agricultural diversions) may also be quite different. Although relationships between flow and fish habitat quality have been widely studied in runoff-dominated streams, and a variety of methods have been developed to quantify these relationships (e.g., Stalnaker and Arnette 1976; Morhardt 1986; Instream Flow Council 2002), the applicability of these methods to spring-dominated streams to our knowledge has not been tested.

In this paper, we summarize salient information on spring-dominated streams, addressing the questions of (1) how key habitat components of salmonid fish differ between springand runoff-dominated streams and (2) how changes in flow regime may affect spring- and runoff-dominated streams differently. A framework model depicting presumed ecosystem - flow interactions in SDS is presented and discussed. We then identify and briefly describe several methods we believe are applicable for assessing habitat: flow relationships in SDS. We limit our discussion to cold-water spring-dominated streams and do not review available information on thermal, or hot springs, although they can also influence salmonid ecology (Kaya et al. 1977; Kaya 1978).

\section{ECOSYSTEM CHARACTERISTICS OF SPRING-DOMINATED STREAMS}

Most spring-dominated streams share some general physical characteristics, such as relatively uniform temperature and flow regimes, but they can differ significantly due to both regional and local hydrogeologic conditions. Biotic characteristics of SDS are a function of the habitat created by these physical conditions, as well as effects on species diversity resulting from the location of the streams within a region and a watershed. There are an estimated 65 springs in the United States alone whose average discharges are more than 2.83 cubic meters per second (van der Leeden et al. 1990); the number of smaller springs is substantially greater. A literature derived summary of broad-scale differences in ecosystem characteristics (channel morphology and hydrology, water quality, macrophyte production, riparian plant community composition, macroinvertebrate diversity and density, and fish assemblages and habitat types) of SDS compared to RDS is presented in Table 1; Figures 1 and 2 schematically illustrate these differences.

Most obvious of these characteristics are the stability in discharge and water temperatures that result from a relatively constant supply of groundwater (Figure 3 - hydrograph differences between Spring Dominated and runoff). Since most spring-dominated streams have small catch- 
Table 1. - Habitat attributes of spring-dominated streams relative to those of runoff dominated streams.

\begin{tabular}{|c|c|}
\hline Habitat Attribute & Spring-Dominated Streams \\
\hline Water temperature & - more uniform; typically cooler in warmer months \\
\hline Turbidity & - lower \\
\hline Dissolved oxygen & - typically high, but dependent on source of spring flow \\
\hline Nutrient levels & $\begin{array}{l}\text { - higher } \mathrm{P} \text { in volcanic areas } \\
\text { - lower } \mathrm{N}\end{array}$ \\
\hline Stream flow & $\begin{array}{l}\text { - more uniform, but can fluctuate considerably in conduit flow } \\
\text { springs common in limestone terranes } \\
\text { - timing of peak flows delayed by several months in diffuse flow } \\
\text { springs of western North America }\end{array}$ \\
\hline Channel morphology & $\begin{array}{l}\text { - rectangular shape } \\
\text { - high width to depth ratios } \\
\text { - few bars } \\
\text { - often higher proportion of fine sediments }\end{array}$ \\
\hline Aquatic macrophytes & - typically more abundant and persistent \\
\hline Riparian vegetation & $\begin{array}{l}\text { - herbaceous component dominant; woody component less impor- } \\
\text { tant }\end{array}$ \\
\hline Invertebrate diversity & - often lower \\
\hline Invertebrate abundance & - typically higher \\
\hline $\begin{array}{l}\text { Species dispersal } \\
\text { (between habitats) }\end{array}$ & - lower \\
\hline Fish assemblages & - restricted to cool water fish \\
\hline Spawning habitat & $\begin{array}{l}\text { - very good in many streams (Oregon Cascades) } \\
\text { reduced flushing of fine sediments possible in some springs }\end{array}$ \\
\hline Substrates & - compacted substrates due to calcareous sedimentation \\
\hline
\end{tabular}

ments, extreme high flows typically do not occur. Lack of high flows can result in channel substrate conditions that are poor for spawning when fine sediments accumulate in the bed, but restricted sediment input and bed mobility favors spawning success in a cleaned redd and provide excellent spawning conditions. Channel morphology is also affected by the stable flow regime, with spring-dominated streams having high width to depth ratios, steep banks, rectangular cross-sections, and limited bar development (Whiting and Moog 2001; Whiting and Stamm 1995). Large woody debris usually remains in place and is important in determining habitat complexity and flow patterns within the channel (Figure 2). 


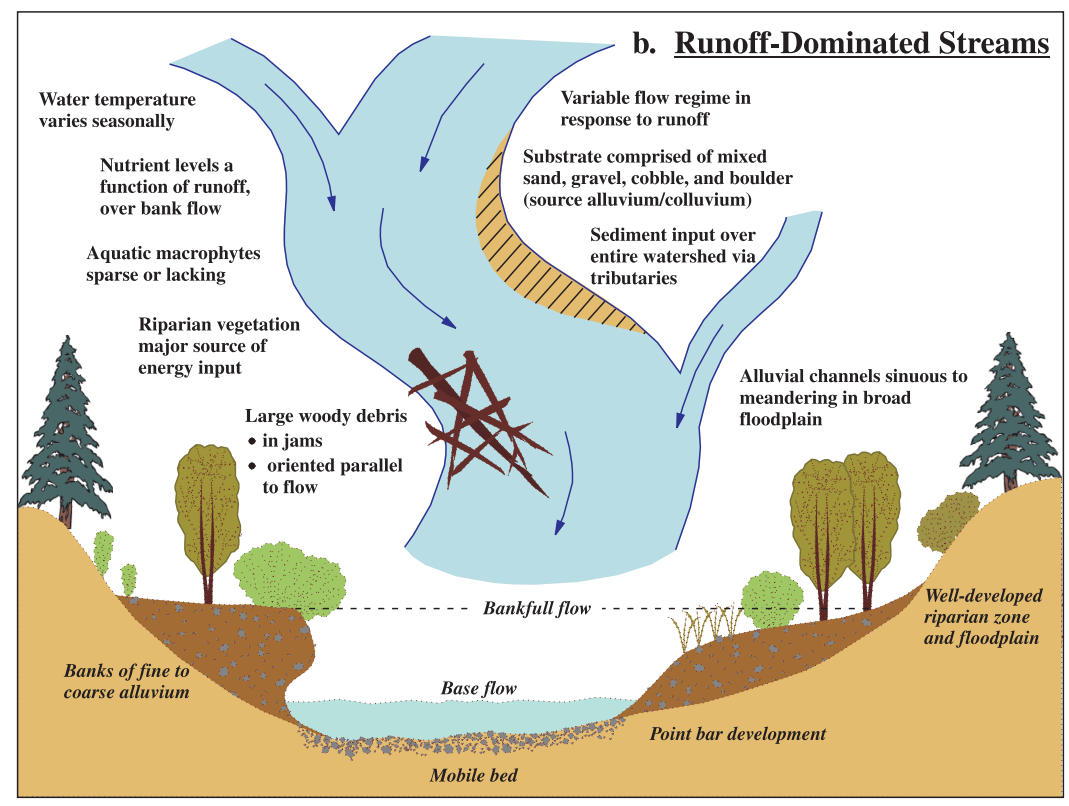

Fig. 1. - Schematic planform and cross-section of a typical runoff-dominated stream depicting representative channel and geomorphologic characteristics.

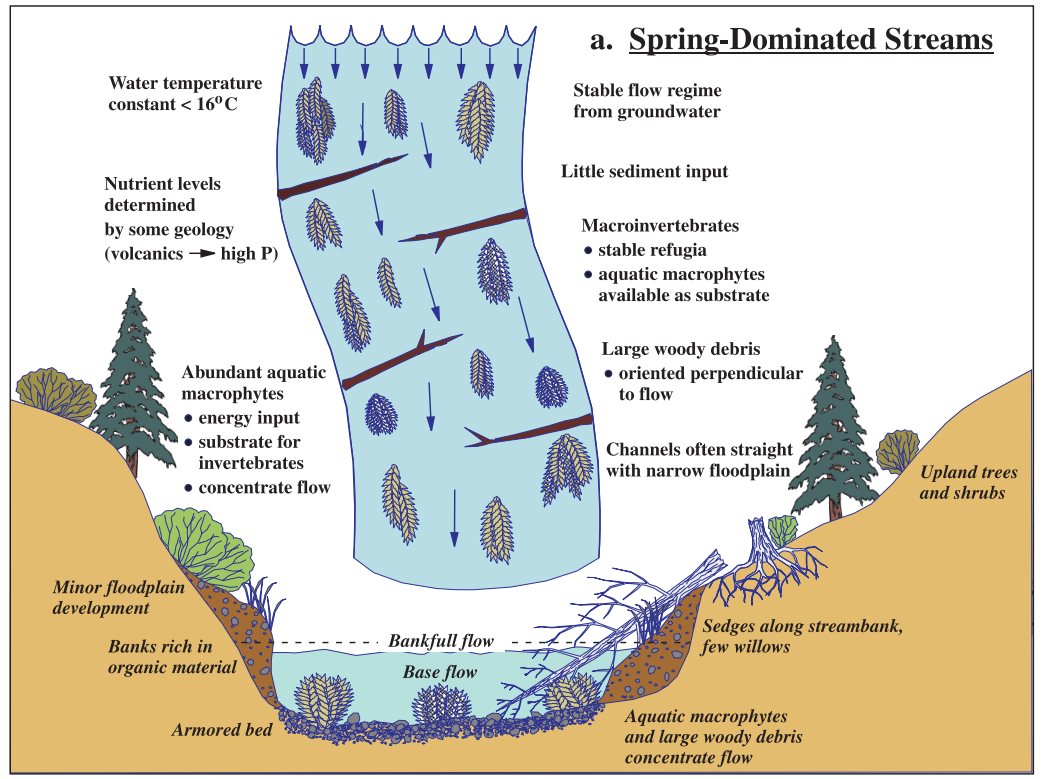

Fig. 2. - Schematic planform and cross-section of a typical spring-dominated stream depicting representative channel and geomorphologic characteristics. 


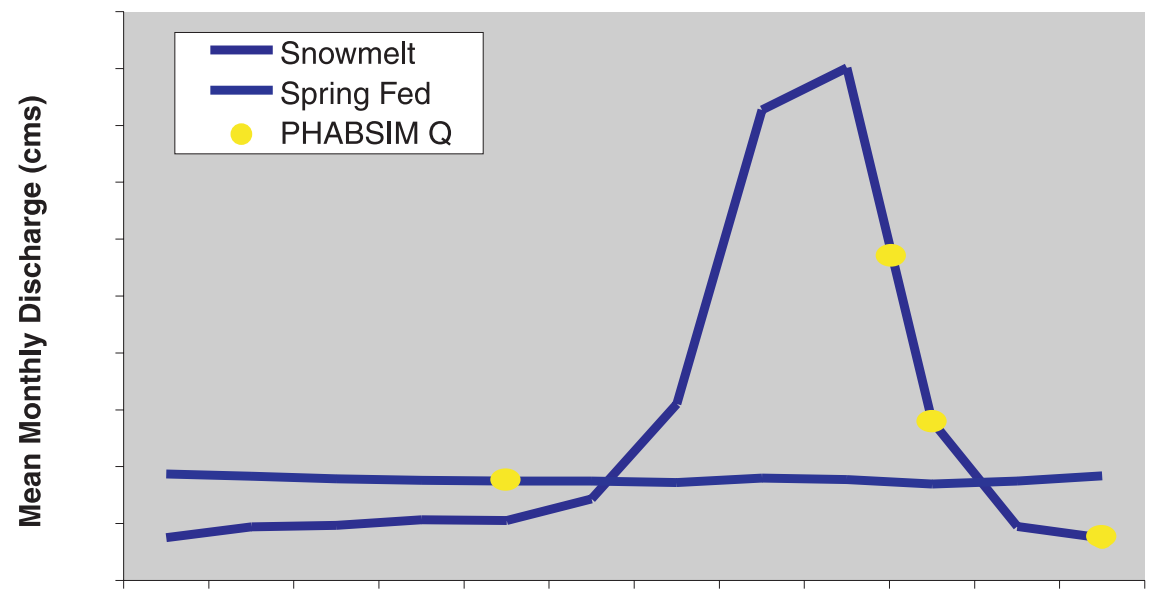

Fig. 3. - Comparison of generalized hydrographs between runoff/snowmelt dominated versus spring-dominated stream systems. Points on lines represent flows on hydrograph that would typically be sampled when conducting a PHABSIM type instream flow analysis. The ability to sample only one flow (due to stable flow conditions) in spring-dominated streams would limit the range of extrapolation possible in the resulting hydraulic models.

The groundwater source results in cooler temperatures in summer and, in colder climates, warmer temperatures in winter. These stable conditions result in a favorable thermal regime for salmonids and other fish requiring cool water in summer. A stable thermal regime also allows spawning in winter, when snow-melt dominated streams are below the temperature threshold for spawning.

Water chemistry in spring-dominated streams is variable and depends on geologic and soil conditions. Spring water is sometimes highly saturated with $\mathrm{CO}_{2}$ or is occasionally low in DO at the source, but these dissolved gases soon equilibrate with atmospheric concentrations. Spring-dominated streams are often low in nutrients, but in areas with volcanic geology can be rich in phosphorus.

Primary productivity, especially of aquatic macrophytes, is often high in spring-dominated streams and can provide a significant proportion of organic material to the stream compared to that in runoff dominated, lower order streams. The importance of autochthonous input of organic material from macrophytes is particularly important in western North America, where high amounts of deciduous leaf litter are not common and woody riparian vegetation along spring-dominated streams is often reduced. Spring-dominated streams, especially in western North America, typically have a well-developed herbaceous 
component, which leads to channel banks that are rich in organic material.

Invertebrate communities in springdominated streams vary in diversity, but commonly have high population levels. The abundance of macrophytic vegetation, which provides food resources, substrate for periphyton, and protection from predators, appears to be a major reason for high invertebrate populations in spring-dominated streams.

\section{FLOW-ECOSYSTEM INTERACTIONS IN SPRING DOMINATED STREAMS}

The importance of flows in maintaining ecosystem function in springdominated streams has not been addressed comprehensively in the literature we reviewed. Quantification of fish habitat using methods such as the Instream Flow Incremental Methodology (IFIM) (Stalnaker et al. 1995; Bovee et al. 1998) has focused primarily on runoff dominated streams. Only one study we are aware of has applied IFIM models to a spring-dominated stream, and that was of a thermal, desert spring (Hardy et al. 1983). Runoff-dominated streams have also been emphasized in determining adequate maintenance flows for channel substrate and geometry (McNamara et al. 2000; Milhous 1998). Since channel conditions and usable fish habitat in spring-dominated streams are not normally subject to the natural range of flows common in runoff- dominated streams, the functional relationship between flow and physical habitat characteristics may be quite different in spring-dominated streams. Because there is, to our knowledge, virtually no information that directly addresses the issue of flow-ecosystem interactions in spring-dominated streams, we are at this time largely restricted to developing hypotheses about these interactions. To that end, this section primarily provides hypotheses about flow-ecosystem interactions in spring-dominated streams based on inferences from known ecosystem characteristics.

Spring-dominated channels are likely to be stable over hundreds, if not thousands of years. They typically do not migrate or avulse, and spring sources are the result of geologic conditions that are not likely to change on time-scales less than a hundred years. Climatic changes can affect discharge, with flows going down during drought periods, but these changes in flow take place over the course of several years to decades. Fluctuations in discharge over seasonal time-scales are low relative to runoff-dominated streams. The channel morphology and substrate conditions are, thus, likely to be in equilibrium with the flow regime, as long as other factors such as local land-use have not recently altered the channel or surrounding area.

Changes in flow pattern in these systems are likely to disrupt this equilibrium, with resulting effects on channel geometry and bed conditions. As in runoff-dominated streams, 
reduced flows could result in a higher proportion of finer sediments settling out (assuming the same level of sediment recruitment), especially in spring-dominated streams that already have a low capability to flush fine sediments. Thus, spawning habitat could become more limited than that found under normal flow conditions in spring-dominated streams.

Reduced flows are likely to result in less habitat complexity available to fish in spring-dominated streams. There is typically limited habitat complexity in spring-dominated streams due to the relatively stable channel geometry with perpendicular banks, lack of channel movement, and reduced riparian cover. Much of the natural habitat complexity to fish appears to be the result of large woody debris that remains in place after falling into the stream or by dense beds of aquatic macrophytes. The high width to depth ratios characteristic of spring-dominated streams results in a relatively uniform and shallow water depth compared to runoff-dominated streams; pool frequency is typically low in SDS. We predict that in spring-dominated streams a lower water surface elevation due to sustained reductions in flow would result in a greater reduction in fish habitat complexity compared to runoff-dominated streams.

Perhaps most importantly, flow levels are likely to have a direct impact on the attenuation of temperatures downstream from the spring source in spring-dominated streams. As flows and therefore the volume of water are reduced, the longitudinal effect of cold water downstream would be lessened, reducing downstream benefits of springs to salmonid fish habitat. In addition, species adapted to constant temperatures may be sensitive to an increased magnitude in temperature fluctuations brought about by seasonal (in the case of irrigation use) reductions in flow. Reduced flow velocities would also tend to decrease turbulence, which is important for reducing dissolved $\mathrm{CO}_{2}$ and total gas pressures and increasing dissolved oxygen levels.

Because aquatic macrophytes in spring-dominated streams are dependent on a stable flow regime, reducing flows to a level that exposes plants or substrates would likely reduce productivity and biomass levels of these plants. A reduction in the amount of macrophytes would likely lead to lower invertebrate populations and less food available to fish. Since in some streams aquatic macrophytes also concentrate flows to increase velocities and flush sediments (Francis and Bjornn 1979), loss of macrophyte biomass could alter substrate composition and spawning conditions. On the other hand, lower velocities and higher water temperatures from reduced flows could favor higher growth of some aquatic macrophytes, as long as water levels remained high enough to submerge plants. This could in turn affect available living space for fish.

Depending on the magnitude of flow abstraction, the resulting re- 
duced flows could also lower the adjacent ground water table and could alter riparian plant communities. If water levels drop below rooting levels of sedges and other water demanding plants along the shoreline, upland plants may replace these species. Furthermore, a lower water table and lack of saturation of bank soils would likely result in oxidation of the organic rich banks and could lead to bank instability.
A conceptual model of flow-ecosystem interactions in spring-dominated streams is shown in Figure 4. This conceptual model emphasizes effects on salmonid spawning and rearing habitat, which in turn controls potential salmonid productivity. Flow reductions result in reduced flow velocity, lower water surface elevations, and higher water temperatures. Each of these direct physical effects results in changes to habitat characteristics,

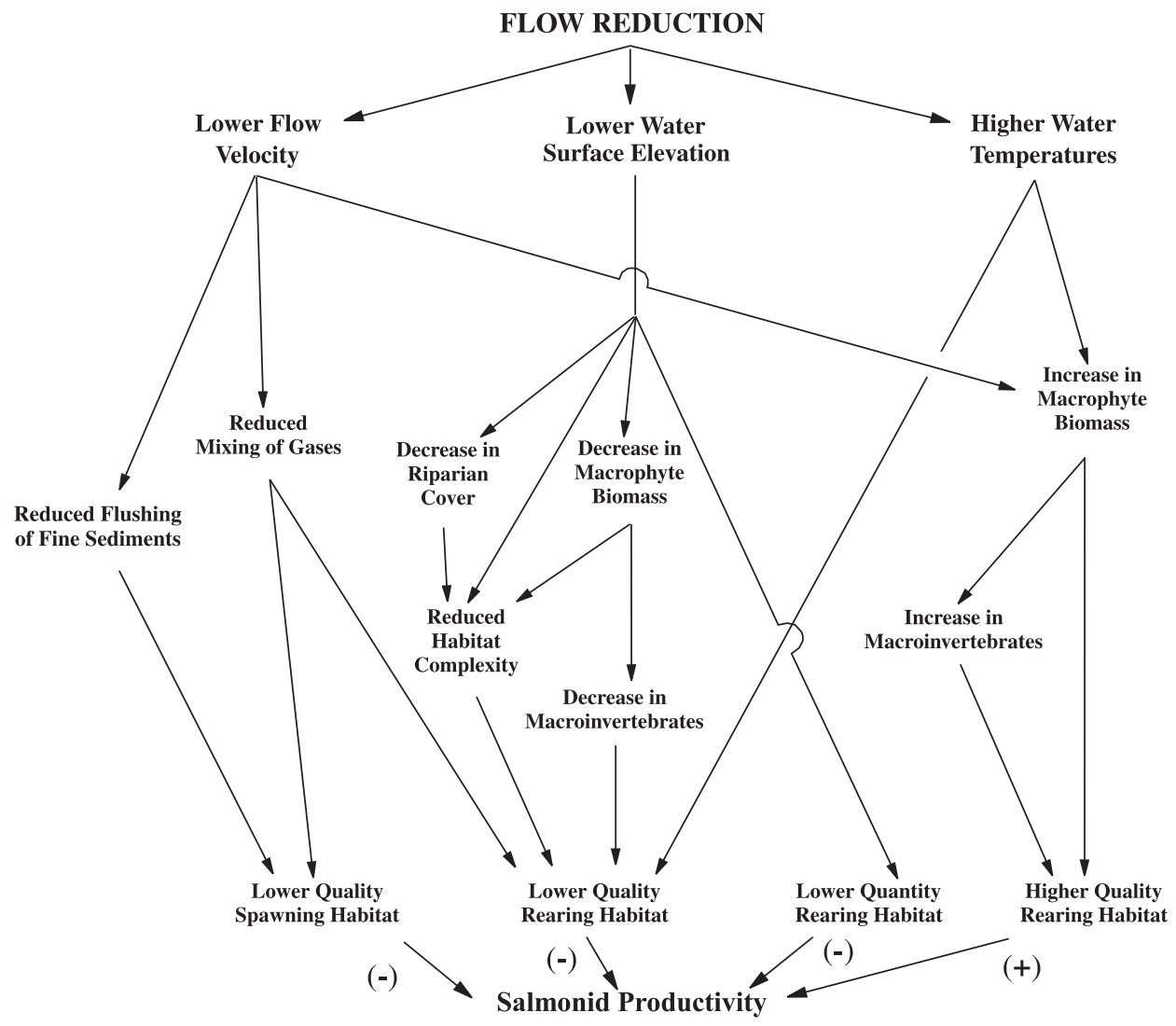

Fig. 4. - Conceptual model of flow-ecosystem interactions of spring-dominated streams with an emphasis on effects of flow reductions on salmonid productivity. 
such as sediment accumulation, reduced habitat complexity, and changes in aquatic macrophyte biomass. As noted above, macrophytes in turn have an important effect on invertebrate abundance. Some of these interactions are similar between spring- and runoff-dominated streams (e.g., lower flow velocity results in reduced transport of fine sediments), whereas others are likely to be relatively more important in springdominated streams (e.g., lower water surface elevation resulting in lower macrophyte and invertebrate biomass). This model shows that flow reduction in spring-dominated streams can have both positive and negative effects on specific habitat components, but that, overall, negative effects outweigh the positive. The model essentially identifies a number of specific hypotheses about ecosystem relationships affected by instream flows in spring-dominated streams. The relative importance of these relationships will likely be site-specific, but they should be useful as a guide to formulate and design studies addressing flow-ecosystem interactions unique to spring-dominated streams.

Manipulations of flow in springdominated streams would likely result in variable conditions of flow velocity, depth, and temperature in a system that is inherently very stable and constant. Such variability would make them more similar to runoff-dominated streams, with a concomitant loss of the characteristics unique to spring-dominated streams. Because the aquatic ecosystems in spring- dominated streams are likely to be in equilibrium with a relatively stable set of flow conditions, changes in the flow regime could lead to disturbance of this equilibrium and changes in many ecosystem characteristics. Patterns of diversity, trophic interactions, productivity, and competition may change, affecting the ecosystem in unpredictable ways.

\section{ASSESSMENT METHODS APPLICABLE FOR SPRING DOMINATED STREAMS}

Some of the more widely applied instream flow methods (e.g., Physical Habitat Simulation (PHABSIM); Wetted Perimeter (Nelson 1980)) require that field measurements be taken at several widely spaced flows. For example, a typical PHABSIM analysis entails measurement of a minimum of three different flows (Figure 3) from which an empirically derived stage-discharge relationship is derived and used for developing a hydraulic model that predicts the vertical distribution of velocities and depths across measured cross-sectional transects. Depending on the range of flows measured, the model can be used to extrapolate flows to some level above and below the highest and lowest field measured flows. When interfaced with appropriate Habitat Suitability Curves (HSC) and habitat models (HABTAT, HABTAV, etc.), it is possible to derive habitat: flow relationships over a relatively 
wide range of flows as depicted in Figure 5.

In streams whose natural hydrographs exhibit seasonal periods of high (e.g., spring runoff; storm event, etc.) and low (e.g., baseflows - fall and winter months) flows, it is a matter of strategic planning of field activities to capture and measure the requisite flows. As well, in regulated systems, there is generally sufficient flow control afforded by dams or weirs such that specific target flows for measurement can be released. However, the development of similar empirically derived relationships in spring dominated streams is inherently problematic due to the stability of flow conditions that would gener- ally preclude measurement of multiple but different flows (Figure 3 ). This is not to say that such relationships can not be developed, but rather that the means to achieve such will in most cases differ from what would otherwise normally be applied.

Fundamentally, when considering flow related effects on spring dominated streams there will generally be less reliance on empirically derived hydraulic models that lead to habitat: flow relationships and more on computer derived models, including those that address sediment transport and channel maintenance. For example, the measurement of a single flow set in a SDS can still be used to develop a hydraulic model (e.g., WSP or HEC-

\section{Weighted Usable Area Curves of Coho Salmon}

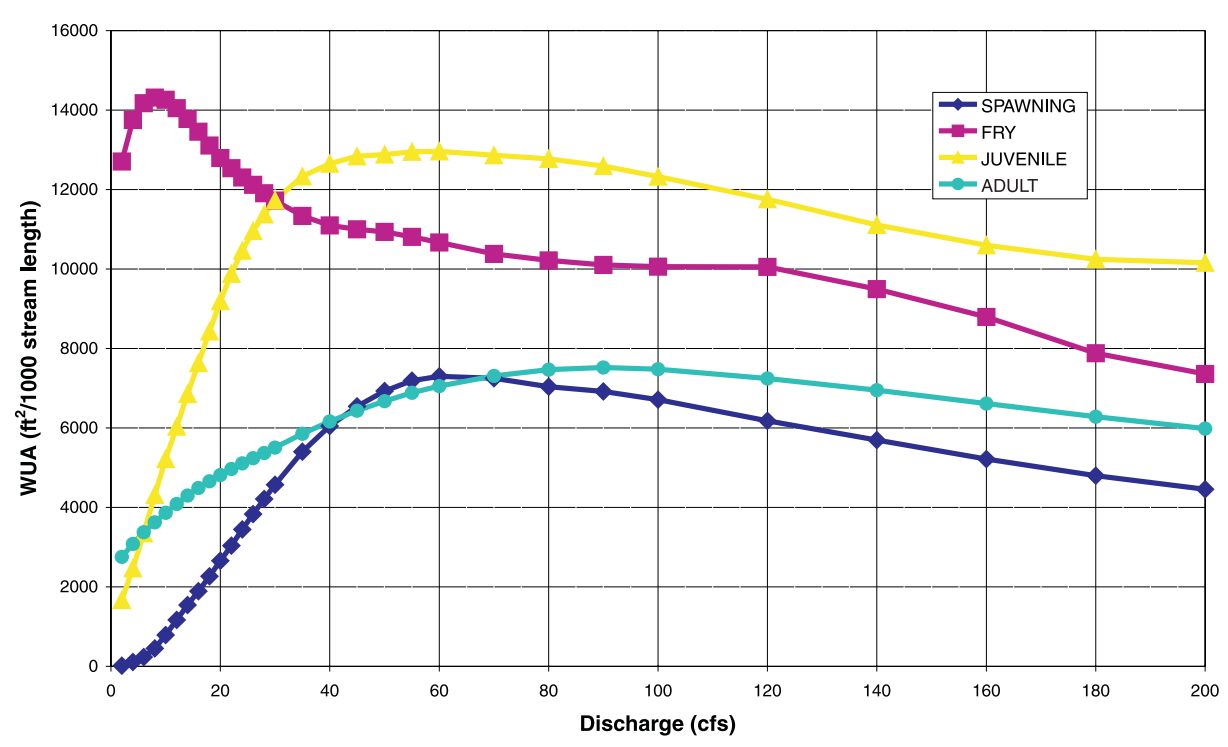

Fig. 5. - Representative habitat:flow relationship for a run-off dominated stream. The range of extrapolation in spring-dominated streams would be much less. 
RAS) that can be linked with habitat to define habitat: flow relationships. However, the range of the defined relationship and hence ability to extrapolate above and below the measured flow will typically be much narrower. Use of 2-Dimensional hydraulic models may be applicable to these systems and could afford a much wider range of extrapolation. However, use of 2-D models would need to consider and account for seasonal growth and senescence of aquatic macrophytes that may complicate bathymetric mapping and velocity fields, thereby increasing the uncertainty in the resulting models. Further, 2-D modeling would be just as incapable as 1-D modeling of simulating velocities within the macrophyte clumps where fish often reside.

Importantly, because of the stable temperature regimes in spring dominated streams, the effects of flow reductions on stream temperature should be given equal priority to efforts focusing on effects on spatial habitats. For this, temperature modeling (e.g., SNTEMP, CE-QUAL-W2, others) may be useful in situations when large flow reductions are anticipated. Temperature monitoring above and below diversion and return flow points may be useful for directly detecting alterations in the thermal regime.

Biological monitoring of spring dominated systems that have or are planned for flow abstractions should also be considered. For example, a Before and After Control Impact (BACl) approach could be useful for assessing potential flow related impacts on various biological metrics including fish abundance and biomass. Our review of the contemporary literature on spring-dominated streams suggests there has been little research done to evaluate ecological effects of flow alterations in these systems. Implementation of carefully designed monitoring programs may provide this information.

\section{CONCLUSION}

Changes in the flow regime of spring dominated streams brought about by water withdrawals will likely lead to both predictable (based on modeling) and unpredictable/subtle (hence the need for monitoring) alterations in ecosystem structure and function. Because of their characteristic stability, we hypothesize that spring-dominated streams are likely more sensitive to changes in flow than runoff dominated streams. Studies are clearly needed to test this hypothesis. Because of this risk, we conclude that the alteration of flows in spring-dominated streams should be done with caution and only after careful consideration of possible ecosystem effects.

\section{REFERENCES}

Bovee, K.D., B.L. Lamb, J.M. Bartholow, C.D. Stalnaker, J. Taylor, and J. Henriksen. 1998. Stream habitat analysis using the Instream Flow Incremental Methodology. Fort Collins, CO. U.S. 
Geological Survey, Biological Resources Division (Information and Technical Report USGS/BRD-1998-0004). 131 pp.

Francis, L.J. and T.C. Bjornn. 1979. Aquatic resources in the Nature Conservancy portion of Silver Creek. University of Idaho, Forest, Wildlife, and Range Experiment Station, technical report $9.84 \mathrm{p}$.

Hardy, T.B., C.G. Prewitt, and K.A. Voos. 1983. Application of a physical habitat usability model to the fish community in a spring-fed desert stream. Pages 391-397 in W.K. Lauenroth, editor. Analysis of ecological systems: stateof-the-art in ecological modeling.

Instream Flow Council. 2002. Instream flows for riverine resource stewardship.

Kaya, C.M., L.R. Kaeding, and D.E. Burkhalter. 1977. Use of a cold-water refuge by rainbow and brown trout in a geothermally heated stream. Prog. Fish Cultur. 39(1): 37-39.

Kaya, C.M. 1978. Thermal resistance of rainbow trout from a permanently heated stream, and of two hatchery strains. Prog. Fish Cultur. 40(4): 138142.

McNamara, M.L., P. Klingeman, P. Bakke, and R.J. Sullivan. 2000. Channel maintenance flows in the Upper Klamath Basin, Oregon. Pages 53-58 in Proceedings of International Conference on Riparian Ecology and Management in Multi-land use Watersheds. August 2000.

Milhous, R.T. 1998. Modelling of instream flow needs: the link between sediment and aquatic habitat. Regulated River Research and Management 14: 79-94.

Morhardt. E. 1986. Instream flow methodologies. Report of research project 2194-2. Electric Power Research Institute, Palo Alto, California (EPRI EA4819).

Nelson, F.A. 1980. Evaluation of four instream flow methods applied to four trout rivers in southwest Montana. Final Report to U.S. Fish and Wildlife Service and Montana Department of Fish, Wildlife and Parks, Bozeman, Montana.

Stalnaker, C.B., and J.L. Arnette. 1976. Methodologies for the determination of stream resource flow requirements: An assessment. Report prepared for the U.S. Fish and Wildlife Service, Office of Biological Services, by Utah State University, Logan, Utah.

Stalnaker, C.B., B.L. Lamb, J. Henriksen, K. Bovee, and J. Bartholow. 1995. The instream flow incremental methodology: A primer for IFIM. Fort Collins, National Biological Service (Biological Report 29). 45 pp.

van der Leeden, F., F.L. Troise, and D.K. Todd. (eds). 1990. The water encyclopedia, Second Edition. Lewis Publishers, Chelsea, Michigan.

Whiting, P.J. and D.B. Moog. 2001. The geometric, sedimentologic and hydrologic attributes of spring-dominated channels. Geomorphology. Volume 39, Issue 3-4: pp 131-149,

Whiting, P.J. and J. Stamm. 1995. The hydrology and form of spring-dominated channels. Geomorphology 12: 233240. 